\title{
Orienting during classical conditioning: Acquired versus unconditioned responding '
}

\author{
RICHARD L. PATTEN AND JERRY W, RUDY \\ UNIVERSITY OF RICHMOND
}

Orienting behavior of turning toward and approaching the conditioning stimulus (CS) during classical conditioning was observed. Animals undergoing classical conditioning developed orienting behavior over trials while control animals showed habituation of unconditioned orienting to the CS.

While studying salivary conditioning, Pavlov (1927) noted that a novel extraneous stimulus would elicit head and body movements toward the new stimulus. He used the terms "investigatory reflex," "what is it?" or "orientation reflex" in referring to this phenomenon. Subsequent investigation 2 of the overt behavior and physiological components of the "what is it?" have shown the reaction to adapt out after 15-20 presentations of the stimulus. However, these investigations have not been conducted in the context of appetitive classical conditioning.

Alekseeva (1956) and Zener (1937) made qualitative reports of the development over trials of movements toward the CS. In these studies, however, orienting toward the paradigm CS was greatly interfered with by the development of orienting toward cues of the always-present food pan into which the UCS was delivered. The conditioning technique used in the present study eliminates orienting toward competing sources of stimulation and thus permits a quantitative investigation of a possible distinction between "what is it?" and acquired orienting toward a new stimulus serving as a $\mathrm{CS}$ in classical conditioning.

Two kinds of data were collected in the present study: (1) Orienting responses toward the CSby a group of Ss undergoing classical conditioning and by two control groups of Ss. (2) The development of conditioned licking, to provide information on a possible relationship between conditioned licking and orienting in conditioning Ss.

\section{Method}

The Ss were 24 female Long-Evans Hooded rats 120-130 days old, eight of which were assigned at random to a classical conditioning group (CC), eight to a pseudoconditioning control group (PC), and eight to a no-UCS control group (C). All Ss were adapted to a $23 \mathrm{hr}$. water deprivation regimen for five days prior to experimentation and were deprived of water for $22 \mathrm{hr}$. preceding each daily experimental session. The apparatus and procedure were essentially the same as in a previous study (Patten \& Deaux, 1964) with minor exceptions. The UCS delivery tube was supported entirely by the leather and stretch-nylon head harness. During conditioning, Ss were allowed free movement on a 23 in. $x 17$ in. platform, with the CS (a 4 sec. illumination of a partially darkened $15 \mathrm{w}$ bulb) located 5 in. above the edge of a long side. Licking was recorded for all Ss during a 3 sec. period preceding CS-onset and during the first $3 \mathrm{sec}$. of CS-on. For group CC Ss, the lick recording period terminated with delivery of the UCS, which was $.40 \mathrm{ml}$ of water over the last $1 \mathrm{sec}$. of CS-on. Licking responses by control Ss were recorded on CSalone trials. During each of 11 daily experimental sessions, group CC Ss received 25 paired CS-UCS presentations with intertrial intervals (ITIs) of 45,50, and $55 \mathrm{sec}$. arranged in a modified random sequence with a mean of $50 \mathrm{sec}$. The ITI schedule was modified to exclude a continuous sequence of three or more identical ITIs. On experimental day 12 , group CC Ss were given 10 conditioning trials followed by an extinction series of $20 \mathrm{CS}$-alone trials. For the first 11 days, group C Ss received the $\mathrm{CC}$ schedule of ITIs and CS presentations, but did not receive the UCS until day 12 , when they received 25 CS-UCS pairings. PC Ss received 50 randomly ordered presentations of CS and UCS (25 of each) per day in a modified random interstimulus interval schedule of 20,25 , and 30 sec. with a mean of $25 \mathrm{sec}$. On day 12, PC Ss were switched to the conditioning schedule for $25 \mathrm{CS}$-UCS pairings.

\section{Results and Discussion}

The licking data obtained in the present study were comparable to the Patten and Deaux data and so will not be discussed.

Two measures of orienting behavior were taken. First, a "facing" response was recorded for those trials on which $\mathrm{S}$ faced the CS during the first $3 \mathrm{sec}$. of CS-on. To qualify as a facing response, an acute angle between $S$ 's line of sight and a line extending from the CS to S's near eye was required. Second, a "transition" response was recorded during the CR scoring interval for those trials on which $\mathrm{S}$ moved hils head and both front feet laterally toward the CS, or, if already facing the CS, when $S$ moved toward the CS across prescribed areas marked on the platform. Using a center point directly below the $\mathrm{CS}$, an 8 in. diameter half-circle (line 1) was marked on the platform. A second 16 in. diameter half-circle (line 2) was drawn around the CS in the same manner. To make a transition response, $S$ had to move his head and both front feet toward the CS across at least one of these lines during the first $3 \mathrm{sec}$. of CS-on. Since the facings and transitions measures of orienting produced identical patterns of results, only the facing data is presented in Fig. 1.

Individual daily percentage orienting scores were arcsine transformed for use as units in statistical analysis. Mean daily arcsine scores for each group are 


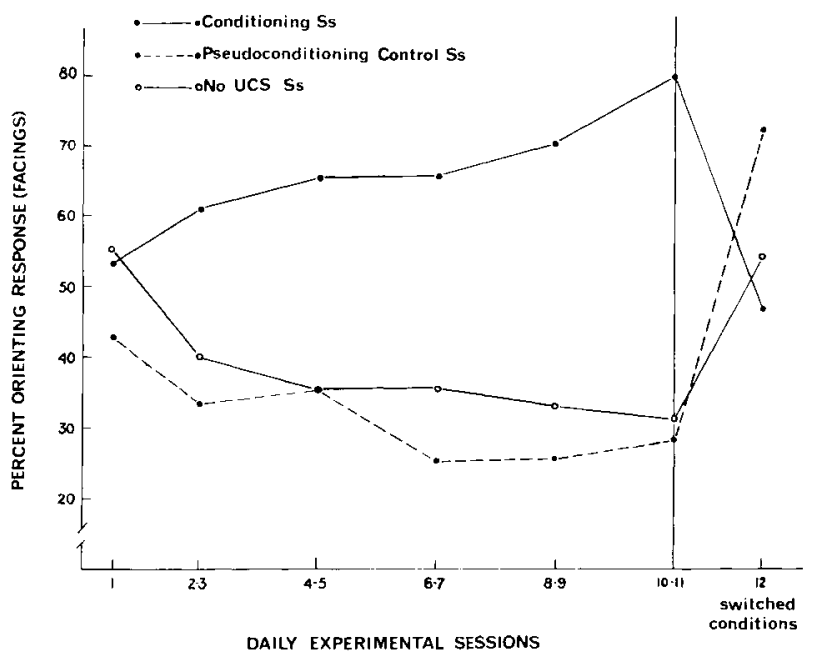

Fig. 1. Orienting responses (facings) by conditioning and control Ss.

plotted in Fig. 1 with the corresponding percentage values indicated on the ordinate. All tinree groups of Ss begin with a relatively high level of orienting on day 1 (relative to days 10-11 level of both control groups), with a subsequent decline in orienting by control Ss and a gradual increase in orienting by conditioning Ss. The comparison of group $\mathrm{CC}$ and group $\mathrm{C}$ performance over the 11 days was significant $(F=56.9, p<.01)$, as was the groups ( $C$ and $\mathrm{CC}$ ) by days interaction $(F=4.74, p<.01)$. The comparison of group $P C$ and group $C$ performance over the 11 days was also significant $(F=5.1, p<.05)$, but the groups ( $P C$ and $C$ ) by days interaction was not significant. The group $\mathrm{CC}$ increase in orienting is regarded as acquired orienting, while the group $\mathrm{C}$ decline in orienting is regarded as habituation over days of the "what is it?".

The fact that PC Ss oriented less than C Ss may be related to the correlation of the CS with nonreward in the pseudoconditioning control procedure. A sampling bias interpretation of this C vs. PC difference is not supported by the within-session data for day 1 : the first block of five trials reveals an initial nonsignificant PC superiority ( $58 \%$ vs. $54 \%$ ) which is followed by reversal and increasing superiority of group $\mathrm{C}$ orienting on the following four blocks of five trials. The transitions measure produced a matching pattern of results here as elsewhere. The writers prefer to regard the present data as suggesting the possibility of "negative orienting" to a cue paired with nonreward. The differences between days 10-11 and day 12 orienting indicated in Fig. 1 were significant at the .01 level for all three groups.

A "reinforcement" account of acquired orienting would emphasize the accidental contingency between an orienting response and the subsequent occurrence of a primary reinforcer (the UCS) or a secondary reinforcer (the CS). The initial high level of unconditioned ('what is it?') orienting results in a temporal response- reinforcement relationship, i.e., selects the orienting response from alternative responses as the one followed by reinforcement. However, this approach has some difficulty with the fact that control Ss show rapid acquisition of orienting when switched to conditioning in spite of habituation of their "what is it?". It must be mentioned, though, that a low level (approximately 10\%) of between-session spontaneous recovery and withinsession habituation of unconditioned orienting by $\mathrm{C}$ and PC Ss showed no signs of diminishing over sessions. A more promising account of acquired orienting appears to lie in the neo-Hullian (e.g., Spence, 1956) concept of incentive motivation. The behavioral effects which define incentive motivation are correlated with the occurrence of a CR $\left(r_{g}\right)$ elicited by a CS previously paired with an appetitive UCS. By an $r_{g}$ account of acquired orienting during classical conditioning, any response that results in increased exposure to the CS is followed by increased elicitation of $r_{g}$, which acts to intensify ongoing responses of turning toward and approaching the CS, etc. This interpretation is consistent with Brown's (1961) suggested application of $r_{g}$ theory to account for some forms of exploratory behavior as well as the emphasis by Miller (1963) and Mowrer (1960) on the importance of motivational feedback in directing behavior.

In order to obtain a measure of relationship between acquired platform orienting and conditioned licking, the number of facings per daily session by group C Ss was subtracted from the number of facings per session by CC Ss to provide a curve of acquired orienting. After partialing out the common correlation with trials, the remaining correlation of $\mathrm{r}=.45$ between acquired orienting and conditioned licking was not significant.

\section{References}

Alekseeva, I. A. Conditioned reflexes to multi-component chained stimuli in conditions of free motor activity. $Z h$. vyssh. nervn. Deitel., 1956, 6, 568-578. (Described in D. Berlyne, Conflict, arousal, and curiosity. New York: McGraw-Hill, 1960.)

Brown, J. The motivation of behavior. New York: McGraw-Hill, 1961.

Miller, $\mathbf{N}$. Some reflections on the law of effect produce a new alternative to drive reduction. In M. R. Jones (Ed.), Nebraska symposium on motivation. Lincoln: University of Nebraska, 1963. Mowrer, o. Learning theory and behavior. New York: Wiley, 1960. Patten, R., \& Deaux, E. Classical conditioning and extinction of the licking response in rats. Psychon. Sci., 1966, 4, 21-22.

Pavlov, I. Conditioned reflexes. (G. Anrep. transl.). London: Oxford, 1927.

Spence, K. Behavior theory and conditioning. New Haven: Yale, 1956.

Zener, $\mathbf{K}$. The significance of behavior accompanying conditioned salivary secretion for theories of the conditioned reflex. Amer. J. Psychol., 1937, 50, 384-403.

\section{Notes}

1. Supported in part by NIMH grant 1B03MH 12569-01.

2. Bibliographies can be found in Berlyne, D., op. cit., and Lynn,

$\mathrm{R}$. Attention, arousal and the orientation reaction. London: Pergamon, 1966. 